\title{
Arquitetura e a construção do espaço Guarani no oeste do Paraná: um estudo de caso na comunidade Guarani Tekoha Añetete
}

\section{Architecture and construction of space in west Guarani of Paraná: a case study in community Guarani Tekoha Añetete}

Gracieli E. Schubert KÜHL*

FAG

\section{Erneldo SCHALLENBERGER ${ }^{* *}$ \\ UNIOESTE}

Resumo: Este artigo resulta de uma pesquisa que teve como objeto de investigação a arquitetura tradicional Guarani e a construção do espaço habitado junto à comunidade Guarani Tekoha Añetete, situada no Município de Diamante do Oeste/ PR. A finalidade do estudo é a de apresentar elementos da arquitetura tradicional Guarani e a relação desta com as questões simbólicas que permeiam as práticas do grupo. Desenvolve uma abordagem interdisciplinar fundada em fontes editas e, sobretudo, nas informações orais e observações de campo. Constata que o universo simbólico Guarani é muito mais significativo para a construção e manutenção da identidade do grupo do que as questões materiais que cercam o seu cotidiano.

Palavras-chave: Cultura Guarani. Arquitetura. Tekoha Añetete.

\begin{abstract}
This article results from a survey that aimed at research Guarani traditional architecture and the construction of the space inhabited by the Guarani community Tekoha Añetete, located in the Municipality of West Diamond / PR. The purpose of the study is to present elements of traditional architecture Guarani and its relationship with symbolic issues that permeate the practices of the group. Develops an interdisciplinary approach based on editas sources, and especially in oral information and field observations. Notes that the symbolic universe Guarani is much more significant for the construction and maintenance of group identity than material issues that surround your daily life.
\end{abstract}

Keywords: Culture Guarani. Architecture. Tekoha Añetete.

\section{Introdução}

Discutir questões relacionadas a cultura e identidade indígenas possibilita ao pesquisador um leque consideravelmente amplo de temáticas.

\footnotetext{
* Mestre em Sociedade, Cultura e Fronteiras. gracischubert@gmail.com

** Doutor em História. erneldo@uol.com.br
} 
Aliando a temática da cultura e da identidade Guarani a questões relacionadas à interdisciplinaridade, cria-se um contexto de pesquisa ainda mais complexo e, por conseguinte, altamente significativo.

A cultura Guarani pode ser considerada uma fonte inesgotável para pesquisas nos diferentes campos das ciências humanas, sociais e aplicadas, entre outras. Ela é composta por símbolos materiais e imateriais, valores e práticas culturais que historicamente foram sendo incorporadas pela tradição e recriadas em situações de convívio dos diferentes grupos, tanto interna quanto externamente, através do contato com outras realidades.

Trata-se de uma cultura que emerge e se apresenta em um determinado espaço social que é, acima de tudo, simbólico e a partir do qual ela se torna fundamental uma vez que, além de justificar ações, possibilita o desenvolvimento e a manutenção dos valores e das crenças dos grupos. No caso dos Guarani, esse espaço coletivo imaginário possui muito mais importância do que o espaço geográfico ou os bens materiais em si. São os bens imateriais as representações, os símbolos incorporados pela tradição às vivências, ao espaço, aos objetos e à arquitetura que possibilitam a legitimação e a manutenção dos valores culturais do grupo. A representação que o material assume encontra-se pautada em uma esfera superior, intangível, qual seja a esfera simbólica.

Os apontamentos que compõem a presente discussão têm como propósito ampliar as possibilidades de conhecimento de aspectos relacionados à cultura Guarani na atualidade e, de modo particular, dos Guarani residentes no Tekoha Añetete. O que se busca é o entendimento da atmosfera simbólica que os envolve na atualidade através de análise da construção do espaço habitado. Os elementos materiais estão sendo focados a partir de objetos cerimoniais e da arquitetura dita 'tradicional' do grupo, com destaque para as características construtivas, materiais e técnicas empregadas, e, sobretudo, nas representações simbólicas presentes em cada elemento incorporado pelos Guarani na construção e no uso desses espaços.

Para desenvolver esta discussão, optou-se metodologicamente por um estudo de caso formulado a partir da etnohistória, baseado em pesquisa de campo junto ao grupo Guarani que habita o Tekoha Añetete, situada no Município de Diamante do Oeste/PR. Este recorte foi instituído pelo fato de esse grupo possuir trajetória peculiar em relação a outras comunidades indígenas paranaenses, circunstâncias estas que, mesmo indiretamente, podem ter provocado alterações significativas em relação ao 'modo de ser' dos Guarani dessa região.

Dentre as ocorrências que diferenciam as comunidades do oeste paranaense de outras há de se considerar, num primeiro momento, a constituição da tríplice fronteira Brasil, Paraguai e Argentina. O território Guarani original, do qual se tem conhecimento, abrangia, embora intermitentemente, a região que cobria quase toda a bacia do Prata, incluindo 
a tríplice fronteira referida. Com a formação dos estados nacionais, esse território, ocupado predominantemente pelos Guarani, foi dividido segundo os novos limites territoriais firmados. Ocorre que os limites impostos aos Guarani, pelo território fragmentado e pela submissão aos poderes nacionais instituídos, os privaram da livre circulação e, ao mesmo tempo, afetaram profundamente seu universo simbólico.

Com a desestruturação do território simbólico original (SCHALLENBERGER, 2006) os Guarani passaram a buscar com afinco o seu novo espaço, entendido não só sob a acepção geográfica, mas, sobretudo, na sua representação simbólica. Em face deste movimento de busca e considerando a importância que o território possui para os Guarani, enquanto lugar de reconhecimento do grupo como unidade cultural, pode-se considerar a possibilidade de que tenham ocorrido alterações substanciais em relação ao seu 'modo de ser', bem como de suas práticas culturais.

No caso específico do objeto do presente estudo, tem-se também o fato de se tratar de indivíduos atingidos pela formação do reservatório da Usina Hidrelétrica de Itaipu, na década de 1980, o que os obrigou a migrar para outros locais e a reconstruir seu espaço habitável.

Estes fatores influenciaram diretamente a delimitação temporal e espacial desta pesquisa, constituindo, portanto, como objeto de análise o Tekoha Añetete, no Município de Diamante do Oeste, situada em região de fronteira internacional. O recorte temporal é fixado no período que se estende dos anos 1970 até os dias atuais, também em função das especificidades citadas acima.

Foram realizadas algumas entrevistas com Guarani que residem na comunidade indígena Tekoha Añetete, das quais são citadas algumas passagens neste ensaio. Porém, sempre que citados, terão seus nomes preservados, indicando somente as iniciais de seus nomes, visando a manter em sigilo a identidade pessoal das fontes.

Sendo assim, os apontamentos que compõem a presente discussão têm como propósito ampliar as possibilidades de conhecimento de aspectos relacionados à cultura dos Guarani na atualidade em relação a práticas voltadas a construção do espaço habitado.

Esses questionamentos serão abordados a partir do viés da interdisciplinaridade, pois se supõe que, através dessa perspectiva, tanto a metodologia quanto as fontes para a pesquisa proposta ganham corpo e se estendem por caminhos flexíveis e bastante atraentes, possibilitando a interação entre diferentes áreas do conhecimento científico. Nesse sentido, é possível integrar diferentes disciplinas em torno do estudo da Cultura, tais como a História, a Antropologia, a Etnografia e a Arquitetura. 


\section{Dinâmica Sociocultural dos Guarani}

Quando se propõe dissertar a respeito de grupos étnicos, faz-se relevante descrever características sociais e culturais presentes na dinâmica interna do grupo, objetivando com isto apresentar aspectos que os identificam, que agregam estes indivíduos em torno de uma unidade cultural, ao mesmo tempo em que também os diferem dos demais agrupamentos semelhantes. Apresentar estas questões possibilita ao pesquisador tecer uma espécie de panorama sociocultural a partir de elementos que compõem a identidade cultural do grupo objeto de estudo e, para o leitor, torna-se possível aproximar-se dos indivíduos apresentados na pesquisa. Serão considerados alguns aspectos relativos aos costumes, às práticas da vivência cotidiana e aos momentos relacionados à religiosidade dos indivíduos que habitam o Tekoha Añetete.

Apesar de ser quase impossível dissociar a vida social da dinâmica cultural dos Guarani, visto que, segundo eles, são características indissociáveis, a apresentação de aspectos relacionados às crenças e aos costumes, sobretudo os voltados à religiosidade do grupo, requer que se considerem os elementos simbólicos e os sinais sagrados presentes entre os Guarani da comunidade analisada. Muitos deles são organizados em torno dos líderes espirituais, chamados rezadores, e associados aos objetos materiais incorporados às cerimônias religiosas.

Na cultura Guarani atual, o rezador é o grande líder espiritual. Possui como função central conduzir e comandar as cerimônias religiosas junto à casa de reza, pela qual é responsável. É o xamoi, aquele que sabe tudo. Dentre os entrevistados para esta pesquisa, encontram-se relatos que apontam o rezador como aquele que possui as armas espirituais para proteger todos da comunidade. É ele quem estabelece comunicação com os deuses para melhor orientar todos do seu grupo. É a pessoa mais importante no interior da organização.

Da mesma forma como o rezador é o grande líder espiritual do grupo, a casa de reza/opy caracteriza-se como o centro religioso da comunidade, onde são realizadas praticamente todas as cerimônias religiosas que compõem o cotidiano Guarani. Pode-se afirmar que a casa de reza, juntamente com os sujeitos que praticam os ritos sagrados, de fato significa o espaço onde a tradição se recria diariamente.

A ideia é de que a opy é tanto um suporte do mundo como a via de contato entre o divino e o humano. (...) O espaço onde a opy se encontra é entendido como o lugar do refúgio e da atualização da memória e da identidade do grupo. É o lugar do sagrado onde os Mbyá podem ter acesso e contato com o mundo divino de forma mais eficaz (ASSIS, 2006, p. 236).

No Tekoha Añetete é possível identificar pelo menos três casas de reza, sendo cada uma delas subordinada a um núcleo familiar. A família do 
entrevistado VV, identificado aqui pelas iniciais do seu nome, por exemplo, possui uma casa de reza, que é comandada pelo seu pai, JV, rezador principal deste núcleo. A família do cacique JA também possui sua casa de reza. A terceira casa de reza foi construída pela Itaipu Binacional e fica próxima ao núcleo dirigido por LCO.

Quando visualizamos determinadas cerimônias indígenas, seja pessoalmente ou através de mídias eletrônicas, podemos perceber a presença marcante da dança, do canto, dos objetos ritualísticos e mesmo da reza na composição do rito. Estes elementos são os sinais que representam algo simbólico, superior e intangível - o universo mitológico dos Guarani. Estes sinais são facilmente descritos pelos Guarani; cada um deles possui uma função marcante no conjunto cerimonial. Os indivíduos envolvidos no ritual identificam-se com estes elementos, adotam postura de respeito, transferem sentidos aos sinais que passam a representar materialmente algo que se encontra em outra esfera, a simbólica.

O conhecimento pleno de um objeto requer, em suma, que o consideremos em seu contexto mais amplo, e em sua característica de sistema (as articulações de significação entre os vários objetos que, relacionados, "falam" sobre as concepções de mundo do grupo social que os produziu), analisando as muitas dimensões e as múltiplas significações que, nas sociedades indígenas, nele estão sempre materializadas e resumidas (SILVA, J; SILVA, A., 2000, p. 372).

Através dos objetos materiais incorporados ao cotidiano dos Guarani é possível analisar inúmeros aspectos culturais e sociais. Por exemplo, ao se tomar como fonte para estudo apenas o “altar” que se encontra na casa de reza, ter-se-ia um enorme leque de possibilidades a serem consideradas.

Em vários relatos presenciados durante as visitas à comunidade, os entrevistados afirmam que os objetos que compõem o altar servem para 'dar força' ao rezador. Com eles e através deles o líder religioso do grupo se comunica com os deuses e é informado dos destinos da tribo, podendo assim, orientar sobre o melhor caminho a seguir. "Ora os objetos rituais agem como variáveis da ideia de esteio (apoio, eixo), ora tem a função de fortalecer, de transmitir energia, força àquilo e aqueles que são suportes do mundo Mbyá” (ASSIS, 2006, p. 185).

Durante pesquisa de campo, foram levantadas questões em relação a estes símbolos tidos como sagrados aos Guarani, dentre os quais os que se referem ao altar da opy, ao mbaraka (chocalho feito com porungo e sementes) e ao takua. Esta simbologia é expressão da cosmologia Guarani. Seguem, portanto, alguns apontamentos extraídos das entrevistas feitas no local.

Em relação ao altar colocado junto às casas de reza, é perceptível a presença de objetos que representam de alguma forma aspectos culturais 
do grupo. Entre eles se encontra um tronco de madeira talhada que comporta a água utilizada nos batismos. Esta madeira é de cedro, que simboliza a saúde, para que a criança batizada não sofra com as doenças durante sua vida. Sem este recipiente com água o batismo não ocorre.

O mbaraka mirim é também componente fundamental para as cerimônias religiosas dos Guarani. Segundo eles, é um elemento ligado diretamente à casa de reza, utilizado para fazer batismos, rituais de cura, entre outros. Afirmam que inclusive as crianças compreendem a função sagrada do mbaraka mirim; quando elas o utilizam auxiliam na sustentabilidade do ritual, fornecendo força ao rezador. Aparentemente os rezadores utilizam o canto juntamente com o som do mbaraka para dar o compasso a toda a cerimônia dentro da casa de reza.

Em uma das atividades junto à comunidade, um dos Guarani citou o processo de transformação destes objetos materiais em representações de algo sagrado. Tomou como exemplo a confecção do mbaraka mirim (chocalho), utilizado durante as cerimônias religiosas. Segundo ele, um mbaraka mirim, confeccionado para compor os rituais, é feito desde o início para este fim; desde a escolha do material até a formatação final do artefato.

Um fato que chama a atenção, principalmente dos não índios quando visitam a comunidade, é a comercialização destes objetos tidos como sagrados para os Guarani. A partir do momento em que um turista adquire este material, o objeto assume outras funções, principalmente como souvenirs. Segundo eles, isto é possível por que estes objetos colocados à venda já são fabricados para este fim. Desde o início da confecção já se estabelece que tal mbaraka seja destinado à comercialização, não passando pelo processo de batismo na casa de reza, sem constituir, portanto, relação com os aspectos religiosos do grupo.

O objeto utilizado pelas mulheres durante as cerimônias é o takua (taquara), que é batido ao chão durante a reza, seguindo o compasso musical do mbaraka e do canto. Ambos os objetos - mbaraka e takua - são inclusive transportados para outras comunidades quando os Guarani as visitam para a realização conjunta de cerimônias.

O batismo pelo qual passam os objetos que são utilizados nos rituais sagrados é denominado de sacralização. Ocorre:

Com a defumação do objeto pelo xamã com seu petyngua. Ao ser investido dessa característica de sagrado o objeto torna-se inalienável, (...), além disso, as coisas sagradas devem ser guardadas e protegidas, pois elas são o suporte material dos valores mais caros do grupo, os valores que contém o sentido de identidade, de coesão (ASSIS, 2006, p. 237).

Este aspecto ligado à sacralização dos objetos cerimoniais representa o que Geertz (1989) define como 'teia de significados' incorporados nos símbolos, nos quais todos os integrantes do grupo encontram sentido. 
Nos cerimoniais a presença dos sinais e dos símbolos religiosos é claramente perceptível. O tronco de madeira colocado junto ao altar é o sinal que remete a algo superior, a um significado cultural que se encontra na esfera simbólica, portanto intangível.

Os objetos rituais no interior da opy (casa de reza), além de serem um suporte material que viabiliza a relação dos homens com a esfera divina, também simbolizam alguns aspectos relacionados à dinâmica e à organização social do grupo. [...] alguns objetos simbolizam o feminino e o masculino, assim como sua complementaridade; simbolizam os papeis sociais de cada um e configuram uma representação [...] do que é o mundo divino que aspiram alcançar (ASSIS, 2006, p. 182).

Observando o cotidiano dos Guarani do Tekoha Añetete, é possível perceber o uso constante de uma espécie de cachimbo, chamado por eles de petyngua. Este objeto também está relacionado a elementos simbólicos, principalmente ao fogo e à fumaça. Eles compartilham o petyngua uns com os outros livremente. Segundo eles a fumaça serve para espantar o mal, para limpar a pessoa de doenças ou outros males que podem atingi-la. É o símbolo das cerimônias de cura.

O petyngua é uma via material para se inspirar, curar e sacralizar as coisas do mundo através da fumaça produzida. A fumaça do petyngua é considerada a forma imperfeita, um duplo do tatachina/névoa vivificadora, princípio vital. É um dos elementos considerado como aquilo que dá vida às coisas, que as anima, assim como possibilita a cura, a revitalização (ASSIS, 2006, p. 183).

O cocar também está presente nas cerimônias religiosas, segundo eles o cocar e o colar são utilizados durante as rezas e, também, na cura de doentes. Quando o indivíduo passa a usá-los estabelece uma ligação direta com ñanderu e já sabe que a cura ocorrerá.

Como se percebe, os objetos incorporados à vivência do grupo expressam os sinais envoltos num universo simbólico derivado dos mitos que sustentam a religiosidade Guarani. Estes sinais estão presentes no imaginário coletivo, transmitido de geração em geração.

Em função de muitas dúvidas, que permeiam principalmente o imaginário daqueles que acreditam que os índios atuais deveriam manter costumes antigos para continuarem a serem índios, cabe citar a definição que este grupo assume sobre o que é ser Guarani atualmente. Segundo um dos entrevistados, o Professor VV:

Hoje em dia o meu pai e a minha mãe são Guarani puro, falam só o Guarani, não falam português, usam os próprios costumes da vida antiga, o fogo de chão, esse é o costume que veio do antepassado (...); o Guarani vem através do conhecimento sobre o costume antigo. Mesmo que fala Guarani talvez 
não sabe o simbólico, vive como o branco (Juruá), este não é Guarani (VV em 20/06/2012).

Eles afirmam que o Guarani atual ostenta adereços diferentes dos da sua cultura original; hoje usam relógio, roupas bonitas, possuem casas boas, porém, sua essência, o seu interior não mudou nem poderá mudar, pois, se isto ocorrer eles deixarão de ser Guarani. As ações do dia-a-dia, os costumes, as práticas, a essência deve ser mantida. Não basta falar a língua ou se vestir como os antigos, é preciso que o interior, o coração não se altere.

Segundo Geertz (1989, p. 26), a antropologia moderna "tem a firme convicção de que não existem de fato homens não modificados pelos costumes de lugares particulares, nunca existiram e, o que é mais importante, não o poderiam pela própria natureza do caso” (GEERTZ, 1989, p. 26).

Pode-se perceber, desta forma, a construção da identidade do grupo em relação a outros indivíduos. Segundo Vicente, não basta somente falar o idioma, ou afirmar que é Guarani, é necessário também cultivar os costumes, conhecer o significado das práticas e reproduzi-las diariamente para não perder a conexão com o passado.

\section{Arquitetura Tradicional: construção espacial do tekoha}

Desde o surgimento da arquitetura enquanto 'arte de construir abrigos’, tem-se como ponto de convergência entre muitos pesquisadores que a construção de espaços, habitáveis ou não, demonstra características culturais específicas da sociedade em que foram construídos. Ou seja, a arquitetura é um produto cultural, pois é resultado da sociedade que a empreendeu segundo as necessidades ou anseios vividos no momento em que a obra foi idealizada.

Sendo assim, é possível afirmar que as obras desenvolvidas pelos Guarani na atualidade são resultado da 'arquitetura tradicional' destes grupos. O termo tradicional é utilizado nesta discussão no sentido de representar os conhecimentos, valores e técnicas transmitidos de geração em geração e que atualmente permeiam o imaginário coletivo dos Guarani integrantes do Tekoha Añetete. As obras identificadas como 'tradicionais' são aqui tratadas como construção de espaços a partir de técnicas arquitetônicas tradicionais, que resultam de ações desenvolvidas ao longo do tempo e que foram sendo adaptadas, aprimoradas e transmitidas historicamente até atingir as características atuais.

Quando se trata de arquitetura tradicional Guarani, deve-se primeiramente rememorar algumas características culturais do grupo. Os Guarani organizavam-se originalmente no espaço a partir da disponibilidade de alimentos. A sua distribuição e a apropriação do espaço 
se dava a partir da fixação de pequenos grupamentos que lhes facultassem o acesso às dádivas da natureza na abundância necessária para a estabilidade dos grupos. Quando o espaço apropriado não mais propiciava o sustento necessário, partiam então para novos lugares, com a finalidade de encontrar a abundância para a manutenção do grupo. Nestes espaços as construções eram bastante rústicas e simples, pois a cada migração eram desmontadas e reconstruídas ou abandonadas. Portanto, estas e outras características influenciaram a forma como os Guarani tradicionalmente desenvolveram sua arquitetura.

Além das questões práticas relacionadas à técnica construtiva, é preciso considerar as transformações ocorridas neste processo a partir dos inúmeros contatos com outros grupos étnicos e, também, as constantes alterações ocorridas internamente como resultado natural das mudanças culturais por que passam os grupos étnicos.

Discutir a arquitetura tradicional dos Guarani na atualidade é, portanto, mais do que refletir acerca das técnicas herdadas dos seus antepassados, que, transmitidas e reproduzidas no tempo presente, representam a arte de construir abrigos. Significa, antes de tudo, demonstrar alguns aspectos relacionados a um processo intenso de contato interétnico com os grupos envolventes, dominados e dominantes, que de alguma forma imprimiram mudanças na formatação arquitetônica que os Guarani definem, na atualidade, como tradicional.

Além disto, o próprio termo tradicional já induz a diferentes interpretações, principalmente quando se trata de pesquisas sob a ótica interdisciplinar. Isto porque, para alguns, o conceito de tradição pode ser considerado estático, enquanto para outros é um aspecto em constante transformação.

Uma discussão breve do termo ‘tradição' nos leva a palavra de origem latina, traditio, que significa transmissão, ou seja, resume-se ao ato de repassar algo para alguém. Em se tratando de cultura, pode-se afirmar que é a transmissão de conhecimentos, práticas e valores de uma pessoa à outra, geralmente estendendo-se por várias gerações.

Tradição possui muitos significados: pode estar atrelada ao conservadorismo e ao resgate de períodos passados considerados gloriosos; pode ser inventada para legitimar novas práticas apresentadas como antigas. Muitas vezes é pensada como imóvel, mas hoje cada vez mais estudiosos percebem suas ligações com as mudanças. Está ligada ao folclore, à cultura popular e à formação de identidades (SILVA, K.; SILVA, M., 2006).

Refletir, portanto, sobre aspectos da arquitetura dita 'tradicional Guarani’ significa esbarrar em questões teóricas e práticas que somente por uma opção metodológica baseada em estudo de caso pode tornar viável a pesquisa científica. Isto porque esta tradição arquitetônica atualmente se 
encontra envolta por tecnologias e materiais não indígenas. Ainda assim, dentre as características próprias da cultura Guarani, facilmente a pesquisa depara-se com divergências nos relatos, mesmo entre depoentes de um mesmo grupo, como é o caso do Tekoha Añetete.

Segundo o antropólogo Rubem T. Almeida (informação verbal1):

É difícil você dizer que existe uma construção arquitetônica Guarani tradicional, porque se você ‘andar’ pelo Guarani do Paraná/ Ilha do Mel, se pensar em Paraná/Pinhalzinho, Paraguai, Guarani do Rio de Janeiro, do Mato Grosso do Sul/Amambaí, você vai ter uma gama enorme de variações. Não se pode afirmar que exista uma construção tradicional. Então como é que eles fazem hoje? Será que hoje eles tendo o material disponível e as condições o que eles fariam? Neste caso a casa do Vicente é típica. [...] Tradicional é pensar como eles constroem hoje.

A definição de 'arquitetura tradicional' adotada para esta pesquisa reveste-se de sentido, portanto, a partir de entrevistas realizadas com os informantes Guarani que residem neste Tekoha. Estes por sua vez indicaram as obras classificadas como sendo tradicionais, bem como suas características. Além disto, foram apresentadas imagens destas construções ao antropólogo Rubem Thomaz Almeida, que acompanhou a trajetória do grupo desde o processo de reivindicação do seu atual território, até pouco tempo, e que reforçou as informações relacionadas a esta análise.

Antes de adentrar a discussão sobre as obras arquitetônicas existentes nesta comunidade, é preciso enfatizar que a casa em si é apenas um elemento que compõe o espaço habitacional construído pelos Guarani, isto porque as funções diárias são desenvolvidas no espaço do 'pátio’/oká, que significa 'fora', 'fora da casa' e não somente na casa de moradia. Para Rubem T. Almeida (informação verbal ${ }^{2}$ ), “A vida social, a vida cotidiana, mesmo a comida é tudo feito no oká, ou no quintal como nós chamaríamos. É esta a concepção que se tem sobre a arquitetura Guarani. Quer dizer, não é só a construção da casa, óbvio que tem o seu sentido também”, porém, deve-se considerar todo o entorno - o pátio em si -, para então compreender a dinâmica social desenvolvida no espaço residencial.

A unidade residencial Guarani Kaiowa e Guarani Ñandeva contemporânea é a família nuclear [xe ñemoña], que é também uma unidade produtiva. Ela tem seu lugar dentro do tekoha (...). Assim, há um espaço para a construção da moradia, para fazer a roça e, sempre que possível, áreas de caça e pesca que sustentam o casal e seus descendentes, quase sempre distante de suas moradias. [...] Em todas as habitações Kaiowa e Ñandeva há invariavelmente o ‘patio’ou oká, não raro com uma ramada ou árvores para abrigo do sol. É uma área limpa em torno das construções e onde se realizam festas e cerimônias, recebem-se visitas, realizam-se encontros e reuniões. É onde o cotidiano se desenvolve de fato, constituindo um 'lugar de estar', com bancos e espaços para sentar, sendo, portanto, público. Nas margens
${ }^{1}$ Entrevista concedida aos autores, em 03 e 04 de janeiro de 2013.

\footnotetext{
${ }^{2}$ Entrevista concedida aos autores, em 03 e 04 de janeiro de 2013.
} 
desse 'pátio', os Ñandeva e Kaiowa plantam ervas medicinais [juju] para uso diário. Em algumas casas a roça fica imediatamente após o 'pátio', ou seja, é uma continuidade da habitação (ALMEIDA, 2001, p. 131).

Uma vez constatado que a arquitetura do espaço habitado Guarani não se resume somente a casa em si, mas ao seu entorno, pode-se introduzir a discussão sobre os materiais e técnicas utilizadas nas construções propriamente ditas que representam a forma 'tradicional' de construção do grupo.

Segundo pesquisas efetuadas, em períodos anteriores, os Guarani construíam e habitavam as casas grandes (ogajekutu), que abrigavam um número expressivo de indivíduos, componentes das famílias nucleares.

Tradicionalmente habitavam casas-grandes chamadas ogajekutu [casa fincada no chão] de um só bloco, sem qualquer divisão interna e paredes que se confundiam com o teto. Eram ocupadas por diversas famílias nucleares, que formavam uma família extensa, centralizada na pessoa de um chefe religioso, o qual dividia a organização política, social, econômica e religiosa do grupo com um líder político a ele subordinado. A ampliação das famílias nucleares correspondia a ampliação da ogajekutu, de maneira que todas as famílias permaneciam dentro dela (ALMEIDA, 2001, p. 125).

Atualmente, os Guarani constroem residências menores e casas de reza - opy. Outras obras praticamente inexistem dentro do espaço de convivência dos grupos. Em relação à técnica construtiva, estas obras apresentam-se de forma bastante simples, deixando para as questões simbólicas a presença mais marcante. Uma característica marcante na organização espacial é a construção de dois espaços considerados residência.

Cada família elementar constrói sua própria habitação, composta de duas construções fechadas [koty], uma ao lado da outra. Uma delas, em geral a mais ampla, constitui o espaço de dormir e é reservada à família. Raramente o visitante, principalmente se não é indígena, tem acesso a koty, local onde a família [ñemoña] toma mate junto ao fogo [tata ypype], nas manhãs ou ao entardecer. (...) A outra construção também serve para abrigar a intimidade das famílias (nucleares), e é onde preparam e consomem os alimentos, funcionando também como despensa para armazenar os produtos da roça, as ferramentas e outros utensílios (ALMEIDA, 2001, p.131).

A partir desta descrição, pode-se tecer uma breve análise desta tipologia construtiva em relação ao que se observa no Tekoha Añetete. A casa, chamada pelos Guarani de 'casa do fogo’, é uma demonstração da arquitetura tradicional, não só em função do material ou da técnica utilizados na sua edificação, mas, sobretudo, em relação ao uso que fazem desta obra.

Em relação à arquitetura dita 'tradicional' dos Guarani, José Perasso e Jorge Vera (1986, p. 95), referindo-se aos pesquisadores que analisaram 
etnograficamente os grupos Guarani Chiripá com sede no Paraguai, afirmam: "Los Chiripa construyen generalmente su og miri / og'i (vivenda familiar - nuclear) con cubierta a doble agua de jahape (imperata brasiliensis - sapê), cerrando las secciones laterales com bambusáceas, gramíneas, yvara e maderas diversas".

Apesar de na atualidade serem avistadas habitações indígenas contendo elementos industrializados, geralmente reutilizados por estes grupos, a construção da residência típica Guarani segue fazendo uso de materiais e técnicas herdados dos antepassados. Basicamente, são utilizados materiais naturais como o sapê, as folhas e o tronco da palmeira/pindo (Arecastrum romanzoffianum), galhos roliços de madeira, cipó e barro.

As paredes são de tronco de pindó (uma espécie de palmeira), cortados longitudinalmente e fincados no chão. Também utilizam como parede, quando há, a takuara batida, que forma placas amarradas à estrutura da casa. O telhado é preferencialmente de sapé, mas as ramas de pindó também podem ser utilizadas, apesar de serem menos apreciadas, por durarem menos (ALMEIDA, 2001, p. 132).

Esta palmeira/pindo possui ligação com a cosmologia Guarani. Segundo os depoentes, ela representa um dos suportes que sustenta o mundo; em função disto a sua utilização na construção da opy é fundamental. Segundo Assis (2006, p. 153), “(...) a denominação nativa de esteio, pindovy, (pindo, palmeira; vy, erguido, ereto, na vertical), expressa claramente a relação entre um e outro".

Em relação à técnica construtiva das obras existentes no Tekoha Añetete, percebe-se que, igualmente como em outras construções, primeiramente é feita a parte estrutural da residência: são cravados no chão madeiras e galhos roliços ou troncos de palmeira na posição vertical, como se fossem colunas para sustentação das paredes; em seguida são afixadas as tesouras na parte superior da obra, com o mesmo material da parte inferior a fim de sustentar a cobertura.

Na imagem 01, a construção da direita apresenta apenas a fase estrutural da obra, enquanto a imagem da esquerda já possui a cobertura e algumas paredes. Esta cobertura mostrada na imagem possui peças de fibrocimento, diferenciando-se das obras tradicionais que utilizam fibras naturais. Ainda assim, a imagem foi mantida como forma de demonstrar a técnica empregada e também para reafirmar a presença de elementos não indígenas nas obras empreendidas pelos Guarani. É possível presenciar esta prática em muitas casas neste Tekoha. Segundo relatos, isto ocorre em função da escassez de materiais na natureza local, levando-os a adotar elementos industrializados. 
Imagem 1 - Elementos estruturais: Imagem contendo duas construções, uma delas apresenta a parte estrutural e a segunda contém a cobertura e algumas paredes. Aldeia Tekoha Añetete, Mun. De Diamante do Oeste/PR, em abril 2012

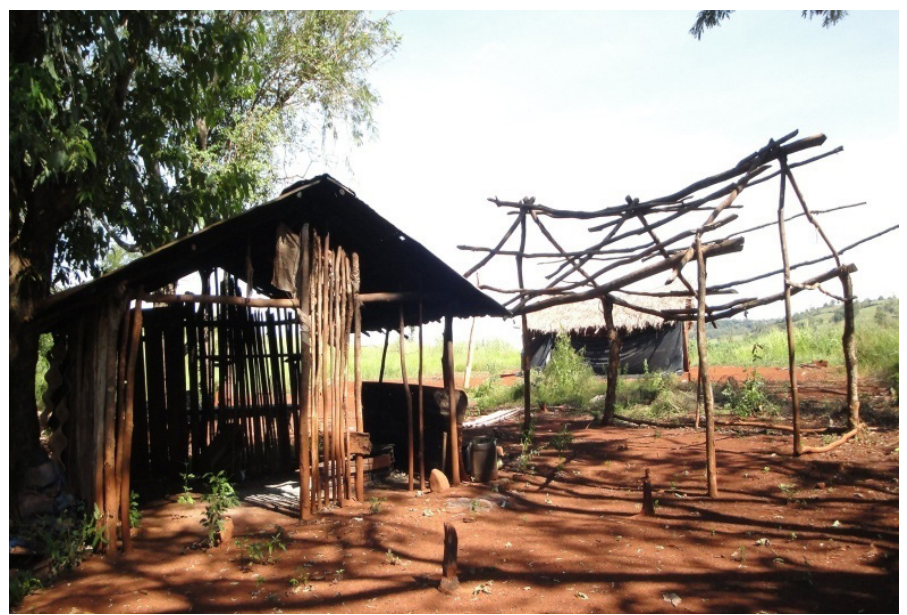

Fonte: Acervo de Gracieli E. Schubert Kühl

As paredes também são feitas com troncos de palmeira ou galhos roliços de árvores, ambos com menor espessura, igualmente fincados no chão e amarrados uns aos outros com cipó preto. Em alguns casos é feito revestimento com um tipo de esteira, uma amarração de filetes de taquara trançados. Em outros casos o revestimento constitui-se de barro, disposto a partir de técnica semelhante às de construções de pau-a-pique, em que a trama de madeira e os galhos roliços ficam entre duas paredes de barro. Segundo relatos colhidos com representantes do grupo, estas duas formas de revestimento são utilizadas com a finalidade de vedação interna, proporcionando maior conforto térmico na casa.

As madeiras utilizadas são o marfim, o angico ou o rabo-de-bugio, pois são mais duras e não permitem que os carunchos as destruam. Esta madeira utilizada na construção é retirada da mata, porém, para isto existe um ritual religioso a ser seguido. Antes da construção da obra em si, é necessário que o rezador local seja consultado. É ele quem dirá se a obra deve ser feita ou não. Em seguida os construtores vão até a mata e escolhem a árvore que melhor se adapta à obra que desejam construir.

Segundo o Professor JA, antes de cortar a madeira eles também precisam ir até à casa de reza para que o rezador peça permissão ao 'dono' daquela árvore para que esta seja cortada e utilizada na obra. Somente depois deste processo é que o material é cortado, retirado da mata e levado ao local da construção. Segundo os Guarani, caso não seja solicitada esta permissão, o dono da árvore poderá trazer coisas ruins aos moradores da casa, inclusive doenças e morte. 
Acobertura geralmenteéfeita com capimsapê(Imperata Brasiliensis) ou folhas de palmeira, conforme disponibilidade no local; são amarradas com cipó. Especificamente neste grupamento, em função da escassez dos materiais acima citados, está se fazendo uso de outro capim nas coberturas, chamado de capim Santa Fé, cultivado no local. Segundo um funcionário da Itaipu que atua nas comunidades da região, existe a intenção de cultivar uma área maior desta planta a fim de haver disponibilidade permanente para atender a demanda das construções.

Segue imagem ilustrando uma residência em construção, onde é possível perceber a composição da cobertura com o referido capim Santa Fé, ainda verde, a colocação das paredes e as amarrações feitas com cipó. Nos exemplos apresentados abaixo, não se fez uso de materiais industrializados, como pregos ou arames. Os materiais utilizados podem ser definidos, portanto, como “tradicionais”.

Imagem 2 - 3 - Construção de residência ‘tradicional’ no Tekoha Añetete. Detalhe: o uso de capim santa fé na cobertura, paredes de roliços e amarrações de cipó. Em dezembro de 2012
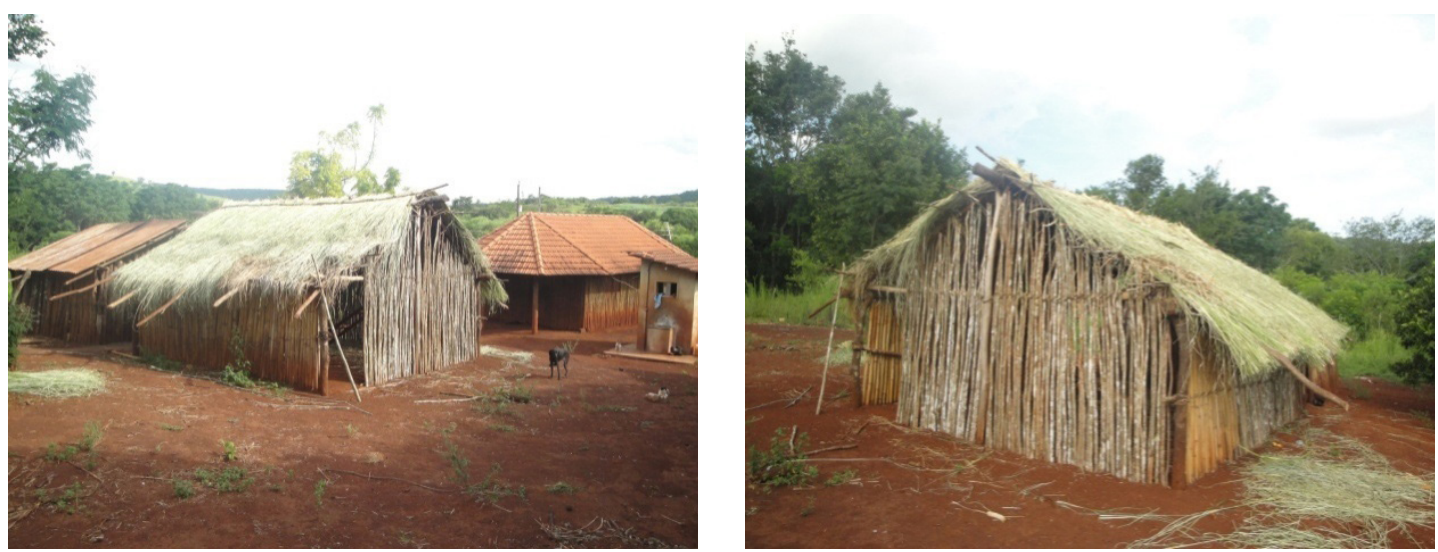

Imagem 4 - 5 - Construção de residência ‘tradicional’ no Tekoha Añetete. Detalhe: o uso de capim santa fé na cobertura, paredes de roliços e amarrações de cipó. Em dezembro de 2012
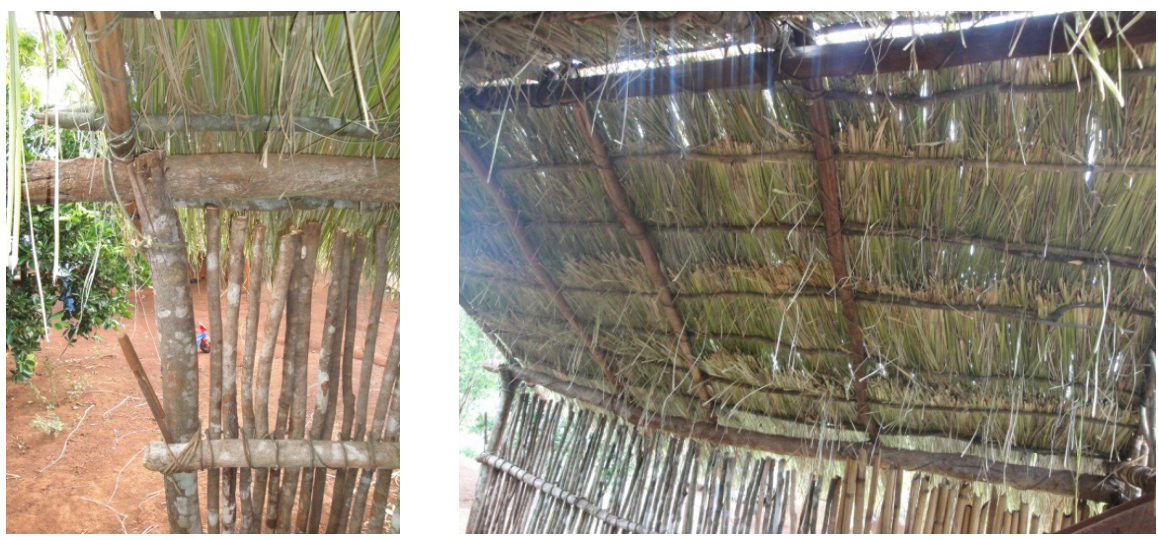

Fonte: Acervo de Gracieli E. Schubert Kühl 
O piso no interior das residências é de chão batido. Esta técnica possibilita outro aspecto ligado à cosmologia Guarani, que é a prática ligada ao fogo de chão. Como já referido anteriormente, a manutenção do fogo de chão está relacionada à manutenção da saúde e à cura de doenças, além do preparo de alimentos, como o milho. A fumaça produzida pelo fogo está relacionada à cura de muitas doenças e outros males que podem acometer os indivíduos.

O interior das construções dos Guarani geralmente não possui divisões; o fogo de chão fica no centro, em torno do qual as atividades são desenvolvidas. Quando ocorrem divisões internas, é para formar o quarto ou cômodo de descanso, de repouso, embora estas situações sejam incomuns.

Originalmente, os Guarani não possuíam camas no interior das casas, somente folhas de palmeira devidamente dispostas no chão, formando uma espécie de colchão. Em período mais recente, é possível encontrar as tarimbas, um estrado de madeira utilizado como cama. Tanto as acomodações feitas com folhas de palmeira quanto às tarimbas são organizadas no entorno do fogo de chão.

Imagem 6 - Imagem atual do interior de uma residência Guarani no Tekoha Añetete, em abril de 2012

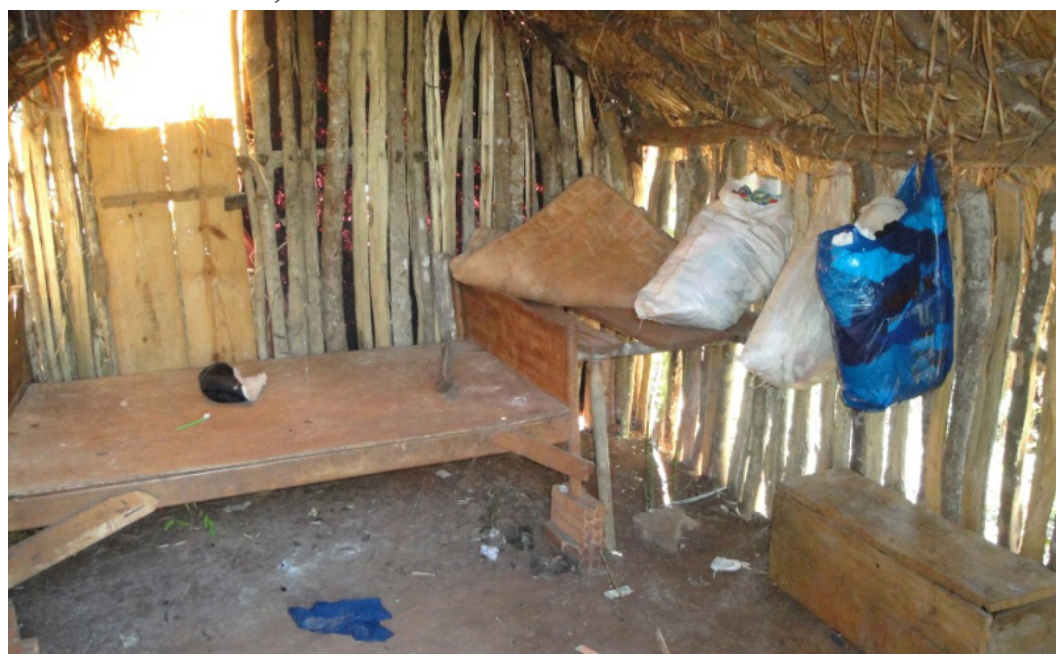

Fonte: Acervo de Gracieli E. Schubert Kühl

Segundo relatos colhidos durante a pesquisa de campo, não é aconselhável a construção de residências ou casas de reza nos períodos em que a lua esteja na fase nova. Recomenda-se que as edificações somente sejam realizadas na lua minguante ou crescente. Isto porque a estrutura da casa torna-se mais forte quando construída nestes períodos, pois o ataque de pragas que danificam a matéria-prima é menor.

A mão de obra para construção é coletiva. O futuro morador conta com a ajuda dos demais membros do núcleo familiar. Quando se trata da 
construção de uma casa de reza, onde é necessária a participação de um número maior de pessoas, ocorre o que alguns autores chamam de potirõ.

O potirõ é uma modalidade social importante para estimular as relações e vínculos entre os grupos locais. Nestas ocasiões estabelecem-se, reforçamse ou reordenam-se alianças políticas e de parentesco. Esta categoria de atividade está pautada no valor do mborayu / reciprocidade, generosidade. (...) É acionado para aquelas atividades que requerem um número amplo de pessoas, para além da família nuclear (ASSIS, 2006, p. 158).

Além das residências, os Guarani constroem as casas de reza/Opy, que são os lugares onde se centralizam as manifestações religiosas e, também, alguns rituais de cura. Cada grupo familiar (ñemoña) deve ter sua casa de reza.

O processo de construção ou de reforma de casas de reza segue calendário próprio e é orientado pelo rezador que recebe dos deuses a indicação da data e do local mais adequado para a edificação. O período indicado para construir é a primavera, isto porque é o período dos batismos; assim a casa fica fortalecida perante a fé Guarani. Além disto, é a estação das grandes cerimônias, pois, além de ser destinada à construção de casas de reza, reúne os rituais de batismo, das sementes que serão cultivadas no próximo plantio e, por isto, é um período que proporciona força espiritual a tudo que se inicia.

A perspectiva cíclica do mundo - na qual tudo passa por uma sequência recorrente de nascimento, amadurecimento, morte e renascimento - presente nas narrativas míticas, aparece desdobrada em várias situações sociais, dentre as quais se inclui a opy. As estações do ano expressam esta concepção cíclica e a primavera é entendida como a época de nascimento e renovação da vida. Este é um período de grande movimentação nas aldeias. É quando intensificam as atividades de tudo o que se refere a esta fase, como a preparação da terra e das sementes (especialmente de avati) para o cultivo, incluindo aí a construção ou reforma da casa ritual (ASSIS, 2006, p. 153).

A técnica construtiva que antecede a implantação da casa de reza é idêntica à das residências; segue o padrão com paredes de roliços de madeira, chão batido e cobertura de fibra vegetal seca. As representações simbólicas encontram-se mais fortemente registradas nestas obras.

O centro do tekoha/aldeia corresponde ao lugar onde se encontra a opy. Possuir um centro parece ser significativo para os Mbyá. O centro significa o eixo, o vértice, a base onde os demais elementos do mundo podem se mover. A palavra opy em sua tradução literal quer dizer casa central, $\mathbf{o}$ - casa e py, centro. Os significados destas raízes lingüísticas, py, centro e y, coluna, viga, eixo a partir do qual algo começa ou se apóia, permitem 
entender a importância dessa idéia no pensamento e no cotidiano social do grupo (ASSIS, 2006, p. 184).

Apesar de toda relevância da casa de reza enquanto local de convergência do grupo cabe ressaltar que visualmente ela não se destaca em meio à distribuição espacial das demais construções no interior de comunidades Guarani. Segundo Assis (2006, p. 151): “os dois tipos obedecem aos mesmos estilos arquitetônico e tecnológico”. A única diferença que pode ser percebida é quanto a sua dimensão, uma vez que ela pode ser maior que as demais o'o/casas a fim de possibilitar o abrigo de todos aqueles que participam dos rituais.

Depois de concluída a casa de reza, coloca-se o altar, que deve conter todos os seus elementos rituais para que a qualquer momento possam ser realizadas cerimônias. Como já foi referido, entre os objetos presentes nos rituais Guarani podem-se destacar o Mbaraka miri / chocalho de uso masculino, Takua / taquara ou instrumento de uso feminino e o cocar.

Em el Nande Ru rog se dispone el tatarendy’y (sitio de las luminárias donde se penden los objetos rituales); el referido apelativo se aplica em forma generalizada as "altar" que se levanta em la sección este. Ñande rovái, donde aparece Kuarahy (Kuarahy oséhápe), ocupando la sección anterior a la batea, ygary ña'e, para la chicha (PERASSO, VERA, 1986, p. 96).

O Professor VV relatou que atualmente os jovens estão desinteressados quanto ao conhecimento das técnicas tradicionais de construção Guarani. Em sua opinião esta técnica deve ser mostrada e ensinada às novas gerações a fim de preservar esta tradição. Muitas construções atuais não seguem, inclusive, os padrões tradicionais; não são orientadas pelo rezador, o que poderá ocasionar má sorte aos futuros moradores, ou, até mesmo, a permanência pouco duradoura na casa.

Uma característica arquitetônica do Tekoha Anetete é a implantação de uma obra 'tradicional' ao lado das construções feitas pela Companhia de Habitação do Paraná/Cohapar e pela Itaipu, também presentes nesta comunidade. Esta obra tradicional caracteriza-se como uma espécie de anexo que na realidade é uma complementação do espaço habitado, do pátio/oká, conforme citado há pouco. Segundo o Professor VV, isto está relacionado à necessidade de preservação das técnicas construtivas dos Guarani. Segundo ele, esta construção, além de ser utilizada para manter o fogo de chão, também tem a função de mostrar aos mais jovens um exemplo da arquitetura praticada por seus antepassados, para que este conhecimento não se perca em meio às construções em estilo não-Guarani, existentes no local. 
Imagem 07 - Residência de VV. Detalhe das duas construções, à frente a casinha do fogo, segundo técnica tradicional (roliços de madeira nas paredes e cobertura vegetal seca) e ao fundo a obra da Cohapar, com as varandas de piso cimentado, paredes de alvenaria até a altura do peitoril das janelas e o restante de madeira com cobertura de telha. Aldeia Tekoha Añetete

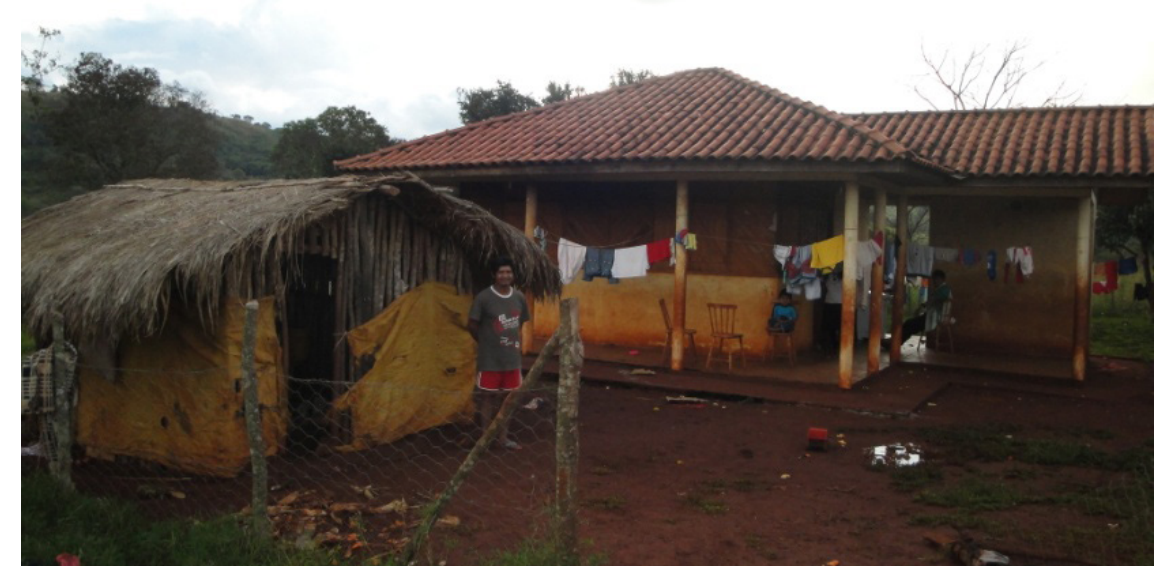

Fonte: Acervo de Gracieli E. Schubert Kühl

Durante o desenvolvimento da presente pesquisa pôde-se constatar que as informações relacionadas ao significado simbólico dos elementos ou mesmo das construções foram referidos por eles, mas de maneira vaga. É possível supor alguns dos motivos que levaram a esta situação; entre os menos prováveis surge o que pesquisadores definem como um 'muro de silêncio' cerceando aspectos da cosmologia dessa sociedade, conforme afirmou Pierre Clastres (1978 apud SANTOS, J., 2012 p. 20). Esta possibilidade se sustenta somente em função do contato estabelecido entre os Guarani e o Juruá/branco desde tempos imemoriais e a resistência criada na sua trajetória histórica. Porém, os momentos de contato com os informantes e demais habitantes da comunidade foram muito proveitosos e em clima de aparente aceitação, sem portanto transparecer qualquer resistência da parte deles.

Outra constatação sugere, portanto, que estes elementos simbólicos constituem um universo realmente cosmológico, do qual decorre a concepção de mundo articulada à vida social, norteando a elaboração de categorias de pensamento locais, bem como de atributos da identidade pessoal e coletiva. Aspectos existentes no imaginário Guarani constituem sistemas praticamente intraduzíveis e que, quando transformados em discurso, em palavras, tornam-se de difícil definição. 
Possivelmente, esta constatação esteja relacionada ao que muitos autores discutem sobre a relação entre símbolo e sinal. Segundo Schallenberger (2009, p. 03), “O símbolo é a melhor expressão de alguma coisa. Enquanto vivo e cheio de significado ele está para além da explicação imaginável. O símbolo nunca pode designar coisa conhecida, pois, neste caso, ele é sinal”.

Aproximando esta discussão ao objeto de estudo, no caso a arquitetura atual dos Guarani e suas representações, os símbolos seriam os aspectos imaginários presentes no uso e nas atribuições da casa de reza, por exemplo, mas que dificilmente podem ser descritos, pois permeiam a consciência desta coletividade. Caso os Guarani atingissem a descrição destes símbolos, eles teriam seus sentidos em parte anulados, pois "uma vez encontrado o sentido que nele é procurado, ela passa a ser símbolo morto que só mais terá significado histórico” (SCHALLENBERGER, 2009, p. 3).

Portanto, ao finalizar esta discussão, ressalta-se que foram abordados aspectos culturais dos Guarani registrados através da arquitetura, sendo esta uma representação do universo cosmológico do grupo, permeada por símbolos que compõem o imaginário coletivo dos habitantes do Tekoha Añetete. Sendo assim, pode-se afirmar que "O símbolo é sempre um produto de natureza altamente complexa que se constitui de dados racionais e irracionais fornecidos pela simples percepção interna e externa, isto é, afeta tanto o pensamento quanto o sentimento, mexe com a sensação e a intuição” (SCHALLENBERGER, 2011, p. 3).

\section{Considerações finais}

Em relação à arquitetura tradicional Guarani propriamente dita, um dos aspectos identificados durante a pesquisa de campo foi a constatação de que para estes grupos a casa enquanto construção arquitetônica é somente uma casca. O mais importante é a simbologia que reveste o seu uso e revela a vida do grupo através das práticas culturais, das cerimônias, dos encontros em que o rezador transmite a palavra e educa a alma.

Sendo assim, é possível concluir que a arquitetura material, aquela que é visível, palpável e descritível não representa tudo aquilo que realmente faz sentido ao 'modo de ser Guarani'. É, portanto, a força das palavras e das ações que justificam toda a dinâmica religiosa do grupo e não as características físicas apresentadas.

Esta arquitetura que nos propusemos a analisar reflete, portanto, uma arquitetura do simbólico, da representação e não do material físico. $\mathrm{O}$ aspecto mais relevante para estes grupos étnicos é a ‘força do sentido’ que se constrói no dia-a-dia, na significação que se cria a partir do uso e das práticas cerimoniais realizadas no local. É uma arquitetura que transcende o material, é imaterial; é o sagrado, o simbólico que se cria lentamente 
através das pessoas, dos ritos, da significação que se incorporam na cultura através das práticas cotidianas.

Acredita-se que fomentar o conhecimento em relação a estes processos é algo importante para esta coletividade étnica, tanto para os habitantes mais jovens quanto para as futuras gerações que povoarão o Añetete e que farão uso destes espaços, ressignificando-os a partir de suas práticas e valores.

Evidente que esta discussão está posta como inicial em relação à gama de possibilidades de pesquisa voltadas a esta temática. Pretende-se, porém, estimular novos trabalhos que tomem como objeto de estudo o Tekoha Añetete, analisando seus costumes, práticas, valores, arquitetura, objetos. Espera-se, enfim, que inúmeras outras pesquisas aconteçam para que este e outros grupos indígenas sejam conhecidos e aos poucos ocupem espaço na historiografia regional.

\section{Referências}

ALMEIDA, Rubem Ferreira Thomaz. Do desenvolvimento comunitário à mobilização política: o Projeto Kaiowa-Ñandeva como experiência antropológica. Rio de Janeiro: Editora Contra Capa: 2001.

ASSIS, Valéria Soares de. Dádiva, mercadoria e pessoa: as trocas na constituição do mundo social Mbyá-Guarani. 2006, 326f. Tese (doutorado em Antropologia). Instituto de filosofia e Ciências Humanas/ UFRGS, Porto Alegre, 2006.

GEERTZ, Clifford. A interpretação das culturas. Rio de Janeiro: Ed. Guanabara, 1989.

PERASSO, José A.; VERA, Jorge. La cultura Guarani en el Paraguay contemporaneo (etnografía ava-kue-chiripa). Assunção: RP, 1987. 272 p.

SANTOS, Jovane Gonçalves dos. Entre homens e diabos: uma etnografia dos Guarani Nhandéva acometidos pelo jepotá. 2012, 152f. Dissertação (Programa de Pós-Graduação Stricto Sensu em Ciências Sociais). Universidade Estadual do Oeste do Paraná/Campus Toledo, Toledo, 2012.

SCHALLENBERGER, Erneldo. O Guairá e o espaço missioneiro: índios e jesuítas no tempo das missões rio-platenses. Cascavel - PR: Coluna do Saber, 2006.

SCHALLENBERGER, Erneldo (org.). Identidades nas fronteiras: território, cultura e história. São Leopoldo: Oikos, 2011.

SCHALLENBERGER, Erneldo. Etnicidade, Fronteiras e Identidades Apontamentos para algumas referências conceituais. Texto apresentado no estágio pós-doutoral em História Cultura e Poder. Curitiba: UFPR, 2009. 
SILVA, Janice Theodoro; SILVAAracy Lopes da. O sistema de objetos nas sociedades indígenas: arte e cultura material. In: SILVA, Aracy Lopes da; GRUPIONI, Luiz Donisete Benzi (org.) A temática indígena na escola: novos subsídios para professores de $1^{\circ}$ e $2^{\circ}$ graus. $3^{\mathrm{a}} \mathrm{Ed}$. - São Paulo: Global. 2000. (369-406).

SILVA Kalina Vanderlei; SILVA, Maciel Henrique. Dicionário de conceitos históricos. São Paulo: Ed. Contexto, 2006.

Data de submissão: 30/04/2014

Data de aprovação: 05/08/2014 